\title{
От редакторов
}

В 2016 г. в «Трудах Института лингвистических исследований» (т. XII, ч. 3) впервые появился специальный балканистический раздел, в котором рассматривался очень широкий круг вопросов, мало связанных друг с другом. Предлагаемые методы также довольно сильно разнились, и статьи объединялись лишь тем, что все они, хотя и в разной степени, были посвящены изучению балканских языков и балканской культуры. В этот раз мы постарались сделать балканистический раздел, базирующийся на материалах прошедшей в 2018 году в ИЛИ РАН конференции «Балканские языки и диалекты: корпусные и квантитативные исследования», более цельным. Авторы вошедших в него статей не просто представляют свои исследования по разным аспектам балканского языкознания, а демонстрируют, какие результаты могут быть получены благодаря использованию новейших лингвистических методов, прежде всего, корпусных и квантитативных. Такие методы еще крайне редко практикуются в современной балканистике, поэтому каждая публикация, связанная с их использованием, представляется очень интересной и актуальной.

Раздел открывает статья П. Асеновой и Х. Марку, где рассматриваются средства выражения эвиденциальности в языках, сформировавших балканский языковой союз. Для своего исследования, помимо собственных полевых материалов и многочисленных публикаций, авторы используют существующие корпуса болгарского, греческого и румынского языков (в том числе диалектные).

С помощью корпусов сербского и хорватского языков и некоторых других источников П. С. Дронов описывает метафорические модели, особенности употребления и лексико-грамматические изменения идиом с компонентами-соматизмами glava 'голова' и vrat 'шея' в сербском и хорватском языках.

В. Дескали составил два корпуса (английский и албанский) общим объемом около 2,2 млн слов из письменных работ албанских студентов, чтобы изучить некоторые особенности лексического выражения модальности. 
Используя данные из Корпуса греческого языка (КГЯ) Ф. А. Елоева и М. Л. Кисилиер анализируют необычное сочетание предлога $\alpha \pi$ ́ с номинативом в новогреческом языке и сопоставляют его с более привычными случаями, когда этот предлог управляет аккузативом.

К. С. Клименок описывает особенности лексической семантики и способы выражения цели и источника при основных албанских глаголах движения shkoj 'идти' и vij 'приходить', анализируя материалы Албанского национального корпуса (АНК).

В коллективной работе А. Л. Макаровой, Д. В. Конёр, Т. Вукович, А. Н. Соболева и О. Винисторфера на примере восточносербского говора села Берчиновац демонстрируется, как метод автоматического языкового анализа может быть применен к диалектному тексту.

Статьи М. М. Макарцева и М. С. Морозовой посвящены разным аспектам комплементации в албанском языке. Для своего исследования оба автора используют материал, полученный из Албанского национального корпуса (АНК).

М. С. Морозова, М. А. Овсянникова и А. Ю. Русаков предприняли квантитативный анализ заимствованной лексики в албанских диалектах. Полученные статистические данные не только подтверждают уже известные наблюдения, но и предоставляют новые данные для изучения языковых контактов на Балканах.

В своей статье Дж. Николс сравнивает разные языковые ареалы по целому ряду морфо-синтаксических параметров. Этот подход позволяет уточнить позицию балканских языков в языковом пространстве Евразии.

Редакторы раздела хотят поблагодарить М. Д. Воейкову и анонимных рецензентов за ценные замечания, которые авторы постарались учесть в окончательных версиях своих статей. 


\section{К проблеме эвиденциальности в языках балканского языкового союза*}

\section{П. Асенова}

Софийский университет имени св. Климента Охридского (Болгария); petyaass@gmail.com

\section{Х. Марку}

Фракийский университет имени Демокрита, Комотини (Греция); cmarkou@bscc.duth.gr

Аннотация. Основываясь на понимании, что категория эвиденциильности не представляет собой балканизма, ввиду отсутствия в отдельных балканских языках единых категориальных и функциональных признаков, доказанных конвергентных движений или какой-нибудь особой «балканскости» по сравнению с остальными языками мира, в статье рассматриваются некоторые средства выражения эвиденциальности в языках, сформировавших балканский языковой союз (БЯС).

Исследование базируется на принятой нами классификации значений эвиденциала, которые можно объединить в три основные группы: ренарратив / «пересказывание», конклюзив / инференциал, дубитатив / (ад-)миратив.

Принимая во внимание типичные для Балкан языковые контакты (особенно в условиях субординационного билингвизма), мы затрагиваем такие мало разработанные проблемы, как: 1) появление способов выражения эвиденциальности в некоторых изолированных балканских диалектах, развивающихся в условиях билингвизма под влиянием болгарского и/или албанского, единственных среди языков БЯС, где эвиденциальность грамматикализована; 2) случаи отсутствия эвиденциальности в албанских диалектах в Греции и в Италии, а также и в болгарских диалектах в Юго-Западной Македонии, Южной Фракии, в области горы Странджа. Существующие объяснения, что в родопских говорах категория исчезла под греческим влиянием, являются неудовлетворительными.

Специальное внимание уделяется лексическим маркерам эвиденциальности, которые анализируются с использованием материалов существующих корпусов

\footnotetext{
* Настоящее исследование осуществлено в рамках научно-исследовательского проекта на тему «Балканские языки как эманация этнокультурной общности на Балканах (типология глагола)», финансированного Фондом «Научные исследования» при Министерстве образования и науки Республики Болгарии - на основании договора о финансировании научно-исследовательского проекта № ДН 20/9/11.12.2017 г.
} 
параллельных художественных текстов. Несмотря на различия между балканскими языками, лексические маркеры эвиденциальности являются сходными или даже идентичными.

На материале корпусов газетных текстов рассмотрены манипулятивные возможности эвиденциальных форм в языке современных средств массовой информации (СМИ): употребление болгарского ренарратива с целью создания дистанцированности или внушения недоверия и иронии; употребление ренарративного кондиционала в румынском для указания на источники непроверенной информации; употребление адмиратива в косовских и македоно-албанских СМИ в качестве репортативной формы с эпистемическим оттенком недоверия.

Ключевые слова: эвиденциальность, ренарратив, конклюзив, адмиратив, балканизм, языковые контакты, лексические маркеры.

\section{On the problem of evidentiality in the languages of the Balkan language union}

\section{P. Assenova}

Sofia University “St. Kliment Ohridski” (Bulgaria); petyaass@gmail.com

\section{Ch. Markou}

Democritus Univeristy of Thrace, Komotini (Greece); cmarkou@bscc.duth.gr

\footnotetext{
Abstract. Proceeding from the understanding that evidentiality is not a Balkanism, as it shows no specificity in the Balkan language union (BLU) in comparison with other languages where this semantic category is expressed and has no common categorical and functional characteristics across the Balkan languages, this article considers some means of expressing evidentiality in the languages of the BLU.

In our study, we distinguish three evidentiality subcategories: renarrative, inferential (conclusive), and (ad-)mirative (dubitative).

Taking into account the typical for the Balkans linguistic contacts (especially in the situation of subordinate bilingualism), this paper considers such understudied problems as 1) the emergence of evidentiality devices in some isolated Balkan dialects developing in a bilingual situation under the influence of Bulgarian and/or Albanian (the only BLU languages where evidentiality is grammaticalized); and 2) the lack of evidentiality in Albanian dialects in Greece and Italy, as well as in Bulgarian dialects in South-Western Macedonia, Southern Thrace, and in the Strandja Mountain area. The existing explanations that this category disappeared in the Rhodope dialects under Greek influence are unconvincing.

Special attention is paid to lexical evidentiality markers analysed here using the existing parallel literary text corpora. Notably, despite the differences between the Balkan languages, they use similar or even identical lexical evidentiality markers.
} 
The paper also addresses manipulative uses of evidential forms in modern mass media such as the use of renarrative in Bulgarian as a means to create a distancing effect or communicate distrust and irony; the use of the renarrative conditional in Romanian to indicate sources of unverified information; and the use of the Admirative in Albanian mass media in Kosovo and North Macedonia as a reportative form with an epistemic nuance of distrust.

Keywords: evidentiality, renarrative, inclusive, admirative, Balkanism, language contacts, lexical markers.

\section{1. Вводные замечания}

\section{1. Проблематика и материал}

В последние десятилетия глагольной категории эвиденциальности, которая интерпретирует отношение говорящего к источнику информации в разнотипных языках, связанных генетическими, географическими или историческими отношениями, посвящена объемная научная литература. Высоко оценивая типологические исследования данной грамматической категории на материале множества экзотических языков (напр. [Aikhenvald 2004; Guentchéva 1996; Guentchéva, Landaburu (éds.) 2007] и др.), мы ставим задачу рассмотреть средства несвидетельской передачи действия в языках, сформировавших балканский языковой союз (БЯС), а именно в албанском, болгарском, греческом и румынском, ориентируясь таким образом лишь на исследования, которые касаются проблематики балканских языков.

В своей статье мы затрагиваем такие мало разработанные до сих пор проблемы, как: роль языковых контактов при функционировании категории эвиденциальности в языках БЯС (Раздел 2); сочетаемость глагольных форм и лексических маркеров с эвиденциальным значением в языках БЯС (Раздел 3); различия между отдельными балканскими языками в плане выражения эвиденциальных значений (Раздел 4); роль эвиденциальных форм в языке современных балканских средств массовой информации (Раздел 5).

В качестве источников иллюстративного материала использовались лингвистические корпусы балканских языков [AHK; КГЯ; CoRoLa], собственные полевые материалы [Рила; Audiolink] и материалы, опубликованные другими авторами (см. список литературы), переводы 
художественной прозы, современная болгарская пресса (см. список источников). Там, где не указано авторство переводов, примеры на русский язык переведены нами.

\section{2. Является ли эвиденциальность балканизмом?}

Из постановки проблемы вытекает и основная цель статьи: рассмотреть статус категории в общебалканском плане и предложить аргументы в поддержку гипотезы, что эвиденциальность не является балканизмом, ввиду отсутствия в отдельных языках балканского языкового союза (БЯС):

a) единых категориальных и функциональных признаков;

б) доказанных конвергентных движений или какой-нибудь особой «балканскости» по сравнению с остальными языками мира.

Мы хотели бы подчеркнуть, что «индуцированные контактами» (англ. contact-induced, см. [Friedman 2008: 141]) грамматикализованные эвиденциальные формы остаются непредставительными для БЯС, поскольку они развиваются, как правило, в небольших островных говорах какого-либо языка или диалекта, разбросанных по территории его распространения и не образующих компактного ареала (напр. в арумынском говоре Горна-Белицы, арум. Beala di Suprâ, в юго-восточной части Северной Македонии). Этот факт заставляет нас не согласиться с утверждениями о существовании эвиденциальности «в языках и диалектах, представляющих все основные языковые группы на Балканах, кроме греческой» [Макарцев 2014: 22].

\section{3. О термине «эвиденциальность»}

Термин «эвиденциальность», предложенный в 1911 г. Францем Боасом [Boas 1911] по отношению к америндским языкам и затем использованный Романом Якобсоном в 1957 г. [Якобсон 1957] применительно к болгарскому, сегодня почти вытеснил более адекватные, по нашему мнению, термины, введенные в конце XIX и в начале XX в. исследователями болгарского и албанского языков (см. [Dozon 1879; Теодоровъ-Баланъ 1887; Трифоновъ 1905; Цоневъ 1910-1911; Weigand 1925] и др.), как, например, утвержденный в болгарской традиции 
термин «пересказывание» (болг. преизказване, англ. reported mood, renarrative, testimonial) или употребляемый Златкой Генчевой, вслед за Жильбером Лазаром [Lazard 1996] «медиатив» (фp. médiatif), т. е. опосредованная передача глагольного действия [Guentchéva 1996: 14]. Поскольку понятия засвидетельствованности / незасвидетельствованности не охватывают все существующие противопоставления эвиденциальных значений с точки зрения источника информации, далее мы употребляем термин «эвиденциальность» в его установленном в современной лингвистике значении.

\section{4. Классификация эвиденциальных значений}

Мы придерживаемся мнения, что эвиденциальность отражает определенное когнитивное состояние говорящего, связанное с приобретением и классификацией передаваемой информации, т. е. то, каким образом говорящий получает информацию: непосредственно - на основе собственного опыта (сенсорным путем) или на основании определенных данных (т. е. посредством умозаключения), либо из слов кого-нибудь другого [Ницолова 2007: 106].

На этом понимании базируется принятая нами классификация значений эвиденциала, которые можно объединить в три основные группы: ренарратив / «пересказывание» (засвидетельствованность / незасвидетельствованность информации), конклюзив / инференциал (умозаключение, основанное на проистекающих из действия фактах), дубитатив / (ад-)миратив (выражение удивления, вызванного данным фактом) [Guentchéva 1996: 15-16; Ницолова 2007: 111; Алексова 2003, 2015, 2016].

\section{5. Эвиденциальность и наклонение}

В нашем понимании, эвиденциальность не представляет собой наклонения глагола, так как эвиденциальные формы не выражают модальности в смысле отношения глагольного субъекта к действию, оценки того, является ли оно реальным, гипотетическим, желаемым, запрещенным и т. д., а передают отношение глагольного субъекта к источнику информации о действии (подробнее см. [Герджиков 1984]). Кроме того, в албанском языке некоторые наклонения имеют адмиративные формы (напр. конъюнктив-адмиратив, кондиционал-адмиратив). 
В болгарском так называемый «аналитический конъюнктив» (сочетание личной формы глагола с частицей $\partial a$ ) тоже может употребляться в сочетании с показателями пересказа:

БолГАРСКИй (балканославянские)

$\begin{array}{lllll}\text { (1) Да } & \text { сме } & c e & \text { били } & \text { навреме } \\ \text { SBJV } & \text { быть.AUX.PRS.1PL } & \text { REFL } & \text { быть.PTCP.PST.PL } & \text { вовремя }\end{array}$

дефолклоризирали щели

дефольклоризировать.PTCP.AOR.PL хотеть.AUX.PTCP.PST.PL

$\begin{array}{llll}\boldsymbol{c} \boldsymbol{c} \boldsymbol{e} & \text { били } & \text { да } & \boldsymbol{c м} \boldsymbol{e} \\ \text { быть.AUX.PRS.1PL } & \text { быть.PTCP.PST.PL } & \text { SBJV } & \text { быть.AUX.PRS.1PL }\end{array}$

се поевропейчили.

REFL европеизировать.PTCP.AOR.PL

'Если бы мы вовремя дефольклоризировались [прошедшее II], то мы якобы стали бы [будущее II] европейцами'. [Тотев 1987]

В албанском языке существуют и формальные признаки эвиденциала как формы, отличной от форм косвенных наклонений. При адмиративе используется индикативное отрицание - частицы $n u k$ и $s$, а не отрицание косвенных наклонений mos.

Несмотря на то, что эвиденциальность не является наклонением, некоторые употребления эвиденциальных глагольных форм не исключают частичного пересечения с модальностью. Это наблюдается в значениях дубитатива и конклюзива, означающих мнение, основанное на собственной инференции [Ницолова 2007: 110].

\section{2. Языковые контакты на Балканах и эвиденциальность}

\section{1. Развитие грамматикализованной эвиденциальности}

В некоторых изолированных балканских языках и диалектах (прежде всего в балканороманских и цыганском), функционирующих в условиях двуязычия, в контакте с доминирующими в социокультурном отношении языками и диалектами (балканославянскими и/или албанским), развились грамматикализованные формы эвиденциальности, которые, по нашему мнению, можно отнести к следующим обобщенным типам: 